\title{
STRATEGI MEMIKAT DAN MEMPERTAHANKAN PELANGGAN MELALUI DIGITAL MARKETING DAN APLIKASI KEUANGAN FINTECH WARUNG JAMU TRADISIONAL PADA ERA PANDEMI COVID-19
}

\author{
Sofiati $^{1}$, Ika Septi Kurnia Anggraeni ${ }^{2}$ \\ ${ }^{1)}$ STIE Widya Wiwaha Yogyakarta, e-mail : sofiatibg25@gmail.com \\ ${ }^{2)}$ Universitas Nahdlatul Ulama Surakarta, e-mail : ika.septi@unu.ac.id
}

\begin{abstract}
The aim of this program is to formulate a strategy to attract and retain customers in bu Hadi's traditional herbal medicine stalls during the COVID-19 pandemic. Forming an independent entrepreneur based on science and technology, improving business management skills for the home industry community in particular traditional herbal medicine drinks in Yogyakarta and creating entrepreneurial training methods suitable for traditional herbal medicine entrepreneurs. The method of recruiting participants through the selection of survey results in several traditional herbal medicine stalls and sellers of jamu gendong keliling in Yogyakarta. The method used in achieving the objectives of the training implementation of this Training Program is the supply through two stages between the first, the supply of materials in tutorials accompanied by discussions, role playing in the location of traditional jamu stalls bu Hadi, both practices guided by the advocate. The target and externality to be achieved from this program is to produce a new independent female entrepreneur based on science and technology in the traditional herbal beverage home industry during the COVID19 pandemic. The outer in the form of services and products of traditional herbal medicine drinks.Keywords: COVID-19 Pandemic, Modern Marketing, Digital Marketing, Digital Financial Technology
\end{abstract}

\begin{abstract}
ABSTRAK
Tujuan program ini adalah merumuskan strategi memikat dan mempertahankan pelanggan di warung jamu tradisional bu Hadi pada saat pandemi COVID-19. Membentuk seorang wirausahawan mandiri yang berbasis iptek, meningkatkan ketrampilan manajemen usaha bagi masyarakat industri rumahan pada khususnya minuman jamu tradisional di Yogyakarta dan menciptakan metode pelatihan kewirausahaan yang cocok bagi pengusaha jamu tradisional. Metode perekrutan peserta melalui seleksi hasil survey di beberapa warung jamu tradisional maupun penjual jamu gendong keliling di Yogyakarta. Adapun metode yang dipakai dalam pencapaian tujuan pelaksanaan pelatihan Program Pelatihan ini adalah pembekalan melalui dua tahap antara pertama, pembekalan materi secara tutorial disertai diskusi, bermain peran di lokasi warung jamu tradisional bu Hadi oleh Pengusul, kedua praktek dipandu pengusul .Target dan luaran yang ingin dicapai dari program ini adalah menghasilkan seorang wirausahawan baru perempuan mandiri yang berbasis iptek di industri rumahan minuman jamu tradisional pada saat pandemic COVID-19. Adapun luaran dalam bentuk jasa dan produk minuman jamu tradisional.

Kata kunci: Pandemi COVID-19, Pemasaran Modern, Digital Marketing, Financial Technology Digital
\end{abstract}




\section{Pendahuluan}

Jamu Tradisional adalah sebutan untuk obat tradisional dari Indonesia. Belakangan populer dengan sebutan herba atau herbal. Jamu dibuat dari bahan-bahan alami, berupa bagian dari tumbuhan seperti rimpang (akar -akaran), daun-daunan, kulit batang, dan buah. Ada juga menggunakan bahan dari tubuh hewan, seperti empedu kambing, empedu ular, atau tangkur buaya. Seringkali kuning telur ayam kampung atau bebek, anggur juga dipergunakan untuk tambahan campuran pada jamu. Jamu biasanya terasa pahit sehingga perlu ditambah madu sebagai pemanis agar rasanya dapat ditoleransi peminumnya. Bahkan ada pula jamu yang ditambah dengan anggur, selain berfungsi sebagai pengurang rasa pahit, anggur juga berfungsi sebagai penghangat tubuh. Dari banyaknya pedagang jamu tradisional di Yogyakarta sangat bervariasi untuk setiap penjaja jamu. Hal tersebut tergantung pada kebiasaan yang mereka pelajari dari pengalaman tentang jamu apa yang diminati serta pesanan yang diminta oleh pelanggan. Setiap hari jumlah dan jenis jamu yang dijajakan tidak selalu sama, tergantung kebiasaan dan kebutuhan konsumen.

Situasi Pandemik COVID-19 memberi dampak yang cukup signifikan bagi Indonesia (Implikasi \& Usaha, 2020) menyebutkan bahwa kajian yang dibuat oleh kementrian keuangan menunjukkan bahwa pandemi COVID-19 memberikan implikasi negatif bagi perekonomian domestik seperti penurunan konsumsi dan daya beli, penurunan pada kinerja perusahaan, ancaman pada sektor perbankan dan keuangan, serta semakin lemahnya eksistensi UMKM di Indonesia.

Mitra yang diajak berkolaborasi dalam hal ini praktisi yang memiliki warung jamu tradisional di Suryatmajan, Yogyakarta. Permasalahan yang ditemukan, sebagian besar pengusaha UMKM kurang memperhatikan strategi pemasaran yang baik khususnya strategi memikat dan mempertahankan pelanggan jamu tradisonal. Akibatnya, saat pandemi COVID-19 banyak warung jamu tradisional yang menutup usaha karena masih melakukan cara tradisional untuk menjalankan usaha. Berdasarkan survey di warung jamu tradisional bu Hadi pengusul menemukan permasalahan bahwa pelanggan jamu di warung bu Hadi sebagian besar adalah ibu-ibu. Di samping itu mereka merasa pembeli maupun pelanggan datang sendiri melalui informasi dari mulut ke mulut dan kalau pasar sedang sepi mereka menganggap belum rejekinya.

Bertitik tolak dari pemasalahan tersebut, solusi yang ditawarkan tim pengabdi adalah memberikan pelatihan tentang manajemen pemasaran khususnya strategi memikat calon pelanggan kaum 
muda yang selama ini jarang ada agar tertarik menjadi pelanggan di warung jamu tradisional bu Hadi. Langkah selanjutnya adalah memberikan pelatihan strategi mempertahankan pelanggan di warung jamu tradisional bu Hadi dengan mengenalkan mengenai digital marketing. Karena banyak kebijakan pemerintah terkait pandemi COVID-19 seperti misalnya PSBB (Pembatasan Sosial Berskala Besar), WFH (Work From Home), SFH (School From Home) dan lain sebagainya, secara tidak langsung mengubah kebiasaan masyarakat Indonesia melakukan aktivitas belanja menggunakan aplikasi digital baik marketing maupun finansial.

\section{Metode Pelaksanaan kegiatan}

Pola pemilihan mitra dilakukan setelah tim pengabdi mengamati potensipotensi dan permasalahan yang dihadapi mitra. Penentuan pola pemilihan mitra ini dilakukan agar program yang telah dirancang tepat sasaran dan sesuai dengan kebutuhan.

Metode yang digunakan dalam melakukan PKM adalah pelatihan disertai praktek, monitoring evaluasi dan pendampingan.Persiapan dalam pelaksanaan pengabdian masyarakat memerlukan survei yang rinci, lengkap, menyeluruh dan selalu memperoleh update informasi. Sebelum sampai pada tahap pelaksanaan, secara berkesinambungan berkoordinasi dan berkonsultasi dengan mitra. Tindakantindakan operasional yang diperlukan untuk mengatasi permasalahan adalah dengan konsultasi dan sosialisasi. Pelaksanaan PKM ini terbagi dalam tiga kategori yaitu pemberian materi manajemen pemasaran dan strategi memikat dan mempertahankan pelanggan jamu tradisional, praktek, dan monev.

PKM berjalan selama 3 hari dengan proporsi jadwal materi PKM 30\%, Praktek dengan praktisi $40 \%$ dan monitoring dan evaluasi (monev). Jumlah peserta pelatihan sebanyak 3 orang yaitu pemilik warung jamu tradisional bu Hadi dan dua orang asisten.

Adapun program pelaksanaan PKM ditampilkan dalam Chart 3.1 berikut:

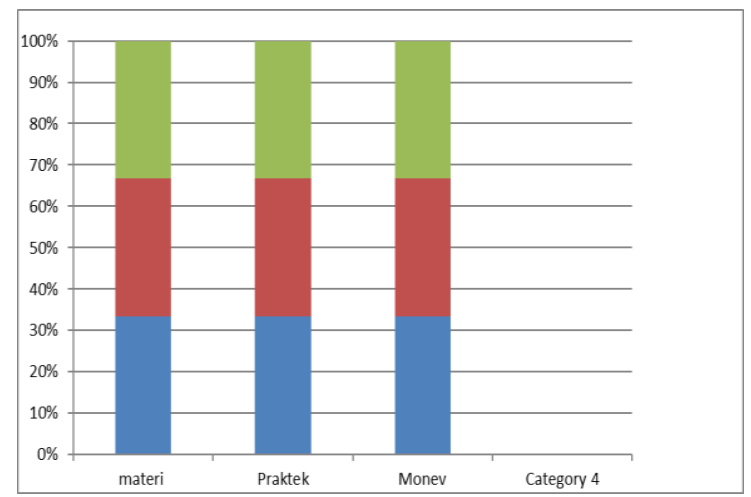

Adapun materi yang diberikan antara lain konsep Pemasaran Online dan Strategi Digital Marketing. Saat pandemi COVID-19 beberapa kebijakan pemerintah seperti 
PSBB (Pembatasan Sosial Berskala Besar), WFH (Work From Home), SFH (School From Home) dan lain sebagainya mau tidak mau membawa pengaruh keputusan belanja konsumen, mereka lebih menyukai melakukan pembelian secara online dan melakukan pembayaran dengan menggunakan E-Wallet. Penelitian yang dilakukan oleh (Suliyanthini et al., 2021) menemukan bahwa perilaku konsumen sebelum dan sesudah pandemi COVID-19 menunjukkan perubahan yang cukup signifikan. Hasil penelitian ini menemukan bahwa sebelum pandemi konsumen dalam mencari informasi tempat, barang dan jasa lebih banyak dilakukan dibandingkan saat pandemi COVID-19, hal ini karena kegiatan seperti mendatangi secara langsung penjualan produk barang maupun jasa. Hal ini disebabkan adanya perubahan kebiasaan pencarian informasi barang maupun jasa kebanyakan dilakukan secara online.

Penelitian Anggraini \& Supriyanto (2019) menunjukkan penggunaan digital marketing di kalangan UMKM masih terbatas karena minimnya kemampuan pelaku usaha. Mereka yang tergolong early adopter, lebih mengoptimalkan Whats App dan Facebook guna membantu transaksi perdagangan. Kesenjangan digital antara laki-laki dan perempuan terlihat dalam penelitian tersebut. Di samping dari kesenjangan pemanfaatan internet, nampak pada peran yang dilekatkan pada perempuan dalam pemanfaatan internet. Ini senada dengan laporan APJII (Asosiasi Penyelenggara Jasa Internet Indonesia) tahun 2016 bahwa 132,7 juta penduduk Indonesia merupakan pengguna aktif internet. Pengguna internet laki-laki kuantitasnya lebih besar, 52,5\% sedangkan perempuan yang memanfaatkan internet hanya $47,5 \%$.

Melihat fenomena di atas, maka tim pengabdi mempunyai inisiatif untuk memperkenalkan pemasaran berbasis online. (Widyartati \& Umkm, 2017) menyebutkan bahwa strategi pemasaran online atau sering disebut online marketing strategy merupakan segala usaha (bisnis) yang dilakukan untuk melakukan suatu pemasaran produk atau jasa melalui media online, yaitu media internet. Penelitian ini menemukan bahwa penggunaan media online mampu meningkatkan laba UMKM. Dengan kata lain strategi pemasaran online secara positif meningkatkan laba pada UMKM. Penjelasan tersebut secara sederhana digambarkan dalam pola pemikiran sebagai berikut :

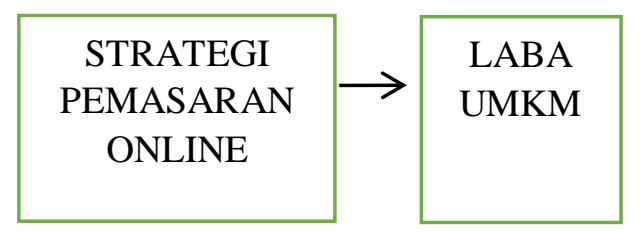


Penyampaian materi tersebut oleh pengusul disampaikan secara bertahap dan diberikan penekanan kepada pemilik usaha jamu tradisional $\mathrm{Bu}$ Hadi bahwa peran pemasaran online saat ini sangat penting untuk meningkatkan laba usaha pada saat pandemi COVID-19. Pemahaman materi tersebut diperkuat dengan mengenalkan aplikasi-aplikasi media sosial seperti misalnya Facebook, Instagram dan kemudian membimbing untuk membuat status penjualan yang menarik perhatian konsumen khususnya untuk generasi millennial. Di samping itu pengusul juga memperkenalkan media pemasaran online seperti Gojek, Grab, Shopee dam toko-toko online lainnya.

Materi kedua yakni tentang Pengenalan Dasar Financial Technology Digital. Dalam pembangunan perekonomian, FinTech dapat membawa peluang dan potensi besar dalam perkembangan UMKM di Indonesia yang pada umumnya memiliki kesulitan dalam aspek keuangan dan permodalan (Ningsih, 2020). Melalui tayangan aplikasi keuangan berbasis teknologi atau FinTech diharapkan permasalahan UMKM di sektor tersebut dapat diatasi. Usaha Mikro Kecil dan Menengah mempunyai peranan besar dalam membangun perekonomian Indonesia.

Menurut (Mangeswuri et al., 2018) penggunaan Financial Technology sebagai instrumen keuangan dalam kegiatan usaha akan membantu para UMKM lebih efisien dalam menjalankan usaha, serta dapat mengendalikan pasar yang memiliki kendala jarak dan waktu. Dengan menggunakan aplikasi keuangan berbasis teknologi ini maka akan menjangkau pasar yang lebih luas bukan hanya business to business tetapi juga business to customers. Selain itu perkembangan FinTech diharapkan dapat membantu pemerintahan Indonesia untuk mewujudkan sistem keuangan yang inklusif.

Sisi lain pembangunan bahwa untuk mencapai cita-cita global SDG's, salah satunya kesetaraan gender, kesenjangan digital ini tidak dapat dibiarkan semakin

lebar. Strategi jitu untuk mengatasinya dengan literasi digital yang menyangkut lima aspek meliputi access, analyse and evaluation, reflection and action (Suwana dan Lily, 2017). Dalam arti, selain dituntunt trampil menggunakan media digital, perempuan dituntut berpikir kritis dan menyelesaikan problemnya dengan bantuan media digital.

Menurut (Suliyanthini et al., 2021) pandemi COVID-19 membuat perilaku konsumen mengalami perubahan yang cukup besar dalam memperoleh barang dan jasa. Hasil penelitian yang dilakukan oleh (Suliyanthini et al., 2021) menuujukkan bahwa indikator perilaku konsumen melakukan informasi barang dan jasa dengan mendatangi 
langsung tempat penjualan pada saat pandemi COVID-19 lebih sedikit dibandingkan pencarian informasi menggunakan aplikasi teknologi internet. Termasuk keputusan-keputusan pembelian para konsumen lebih memilih melakukan dengan sistem online.

Fenomena yang terjadi pada saat pandemi COVID-19 ini secara tidak langsung membuat UMKM yang masih menjalankan usaha dengan cara tradisional lebih memilih menutup usaha, karena selain kendala pada penjualan yang semakin menurun juga memiliki kendala pada sektor permodalan. Dalam situasi ini pengusul memberi pengarahan dan pengenalan secara dasar mengenai Financial Technology kepada mitra. Pengenalan secara dasar aplikasi keuangan berbasis teknologi diharapkan dapat membantu dan mendukung penjualan yang akan dilakukan secara online.

\section{Hasil dan Pembahasan}

Metode pelaksanaan Pengabdian Masyarakat ini dilaksanakan berdasarkan parameter yang dapat dilihat dalam program kerja yang bersangkutan. Melalui mekanisme monitoring dan evaluasi program dilakukan dengan sistem wawancara dengan pemilik warung jamu tradisional bu Hadi dan dua orang asisten, dengan melakukan observasi secara

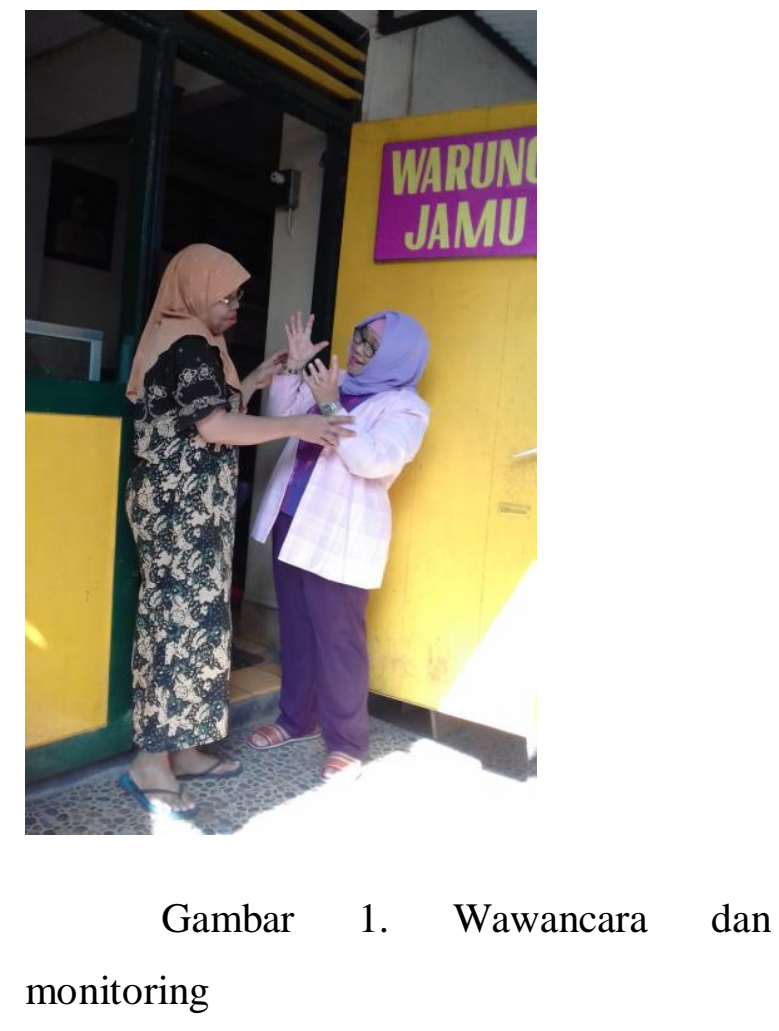

Hasil wawancara menunjukkan bahwa pada saat pandemi Covid-19 tahun 2020, Mitra sempat berhenti menjalankan usaha karena adanya kebijakan PSBB yang sempat diberlakukan di Yogyakarta sehingga tingkat penjualan yang semakin menurun. Hal ini disebabkan karena pelanggan yang membeli langsung mengalami penurunan. Karena belum melakukan sistem penjualan langsung secara online dan masih belum 
memahami cara pembayaran digital yang secara sistematis maka diberikan pelatihan mengenai sistem digital marketing dan strategi penjualan online. Di samping itu juga dilengkapi dengan pelatihan mengenalkan aplikasi keuangan berbasis teknologi.

Pelatihan pendampingan kepada mitra yang diberikan pada akhir tahun 2020 adalah menjelaskan tentang strategi pemasaran yang dilakukan secara online. Perubahan perilaku konsumen yang secara drastis dan cepat pada saat pandemi COVID-19 dalam hal ini lebih suka melakukan pembelian melalui teknologi. Mau tidak mau membuat UMKM yang masih tradisional dalam menjalankan usaha harus mengubah gaya penjualan yang tradisional menjadi lebih modern. Mitra saat ini masih belajar yang lebih modern daripada yang pernah dilakukan. Dari sistem penjualan dan cara promosi lewat media sosial yang sederhana yaitu menggunakan aplikasi whatsapp. Sistem pengantaran barang masih menggunakan system COD yaitu cash on delivery. Dalam jangka panjang penjualan akan lebih banyak dilakukan menggunakan GOJEK atau GRAB mulai pertengahan tahun 2021.

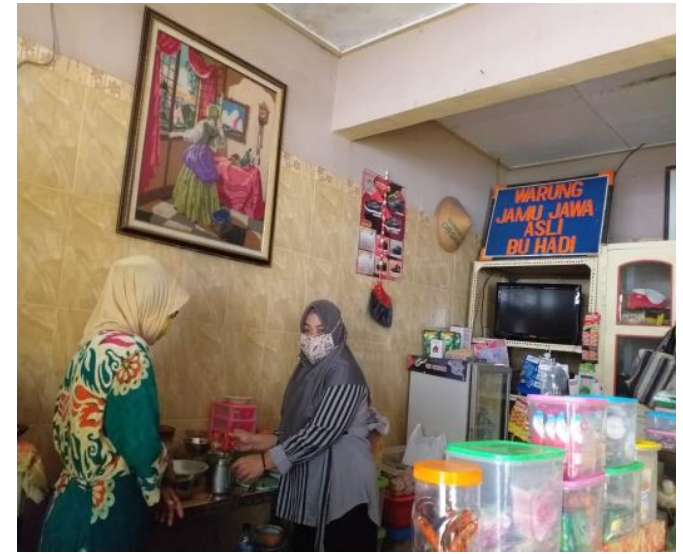

Gambar 2.

Tim memberi pengarahan pentingnya strategi pemasaran

Menurut Media (et al., 2018) media sosial memiliki potensi yang lumayan bagus, sangat bagus/baik, potensi yang sangat besar/ sangat berpotensi sangat berpeluang/menjanjikan dalam usaha kecil menengah. Potensi akan meningkat pada masa yang akan datang. Media sosial memiliki potensi yang sangat cepat untuk informasi pemasaran, testimoni dan masukan dari pelanggan. Media sosial juga mampu mempererat hubungan dengan konsumen dan membantu semua kalangan.

Tabel 1. Alasan media sosial dianggap paling efektif mendukung UKM

\begin{tabular}{|l|l|}
\hline Media Sosial & $\begin{array}{l}\text { Alasan dianggap sebagai media yang } \\
\text { paling efektif }\end{array}$ \\
\hline Facebook & $\begin{array}{l}\text { "Jangkauan cukup luas dan banyak } \\
\text { penggunanya, karena lebih mudah } \\
\text { dan banyak orang yang telah } \\
\text { memiliki akun Facebook. Cepat } \\
\text { berinteraksi dengan orang banyak" }\end{array}$ \\
\hline Whatsapp & $\begin{array}{l}\text { "Facebook dan Whatsapp, karena } \\
\text { jangkauan lebih luas dan langsung } \\
\text { pada "produk say". Kontak dari FB } \\
\text { dan WA rata-rata adalah kenalan } \\
\text { yang sudah dikenal. Fasilitas }\end{array}$ \\
\hline
\end{tabular}




\begin{tabular}{|l|l|}
\hline & $\begin{array}{l}\text { Whatsapp dan FB mampu memberi } \\
\text { jangkauan pemasaran lebih luas } \\
\text { dilengkapi dengan video, gambar dan } \\
\text { lain-lain" }\end{array}$ \\
\hline Instagram & $\begin{array}{l}\text { "Instagram menjangkau pemasaran } \\
\text { untuk generasi muda khususnya } \\
\text { millennial, penggunaan foto dan } \\
\text { video dapat dilihat langsung oleh } \\
\text { customer. Instagram memiliki } \\
\text { interface yang mudah dipahami oleh } \\
\text { para penggunanya" }\end{array}$ \\
\hline Website & $\begin{array}{l}\text { "penggunaan website dilakukan jika } \\
\text { ingin menjangkau pemasaran yang } \\
\text { lebih luas kontennya dibandingkan } \\
\text { media-media sosial lainnya, seperti } \\
\text { misalnya foto produk yang lebih } \\
\text { banyak, informasi detail produk } \\
\text { termasuk kontak penjual" }\end{array}$ \\
\hline
\end{tabular}

Sumber : (Priambada, 2017) (Media et al., 2018)

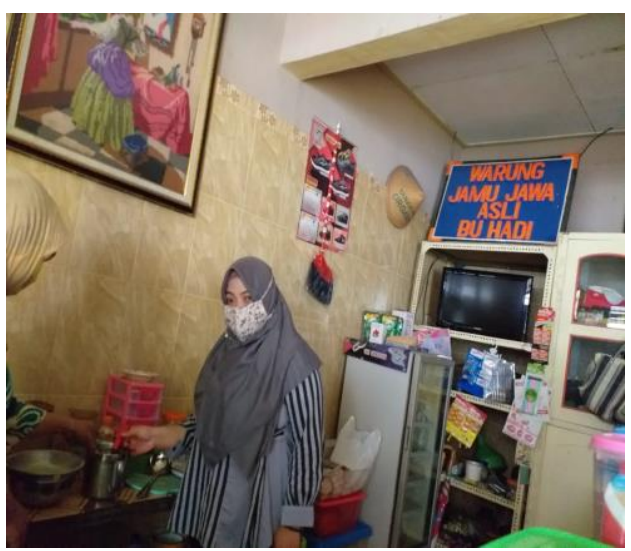

Gambar 3.

Tim memberi pengarahan tentang kemasan untuk meningkatkan strategi penjualan

Pengenalan media sosial kepada mitra termasuk salah satu penjelasan dari strategi digital marketing, Selama ini pelanggan warung jamu tradisional Bu Hadi terdiri dari generasi tua yang dengan kesadaran sendiri datang berkunjung ke tempat usaha untuk membeli secara langsung. Oleh karena itu, tim pengabdi membantu membuat akun media sosial untuk warung jamu tradisional $\mathrm{Bu}$ Hadi dan membantu cara mengoperasikan serta melakukan promosi di media sosial. Hal ini dilakukan secara bertahap sehingga mitra mampu melakukan secara mandiri untuk meningkatkan strategi penjualan yang lebih luas serta membuka sasaran baru untuk generasi muda.

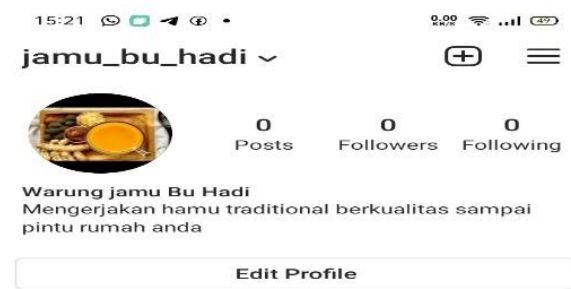

๙

Gambar 4. Salah satu akun media sosial warung jamu tradisional Bu Hadi

Pengenalan mengenai Financial Technology diawali dengan pemahaman dasar mengenai Financial Literacy tentang cara mengelola keuangan dan pengetahuanpengetahuan keuangan secara dasar. Selanjutnya, mitra diberikan penjelasan mengenai Financial Technology dan fiturfitur keuangan secara dasar. Perusahaanperusahaan yang sah di Indonesia menurut OJK dan diberi pemahaman bahaya atau kejahatan jika tidak berhati-hati dalam mengajukan pinjaman melalui FinTech. 


\begin{abstract}
Berikut tabel hasil-hasil dari kegiatan pelatihan digital marketing dan FinTech pada warung jamu tradisional $\mathrm{Bu}$ Hadi

Tabel 2. Indikator Hasil Pelatihan Digital Marketing dan Financial Technology
\end{abstract}

\begin{tabular}{|c|c|c|}
\hline Tahapan & Kegiatan & Indikator \\
\hline Tahap 1 & $\begin{array}{lr}\text { Pengenalan } & \text { dasar } \\
\text { mengenai } & \text { digital } \\
\text { marketing } & \end{array}$ & 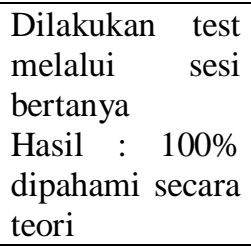 \\
\hline Tahap 2 & $\begin{array}{l}\text { Pengenalan media } \\
\text { sosial dan cara } \\
\text { mengoperasikan }\end{array}$ & 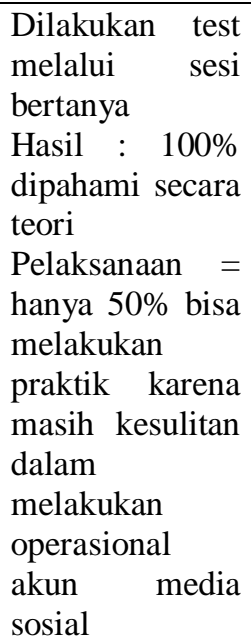 \\
\hline Tahap 3 & $\begin{array}{l}\text { Pelatihan mengenai } \\
\text { cara promosi melalui } \\
\text { akun media sosial }\end{array}$ & $\begin{array}{l}\text { Dilakukan test } \\
\text { dengan praktek } \\
\text { melalui } \\
\text { handphone dan } \\
\text { media sosial } \\
\text { Hasil = hanya } \\
50 \% \text { bisa } \\
\text { melakukan } \\
\text { praktik karena } \\
\text { masih kesulitan } \\
\text { dalam } \\
\text { melakukan } \\
\text { operasional } \\
\text { akun media } \\
\text { sosial }\end{array}$ \\
\hline Tahap 4 & \begin{tabular}{lr}
\multicolumn{2}{l}{ Pengenalan FinTech } \\
secara dasar & dan \\
pemahaman & \\
kejahatan & P2P \\
lending & (fitur \\
peminjaman) &
\end{tabular} & $\begin{array}{lr}\begin{array}{l}\text { Dilakukan } \\
\text { melalui }\end{array} & \text { test } \\
\text { bertanya } & \\
\text { Hasil = } & \\
\text { memahami } & \\
\text { secara teori } & \\
\end{array}$ \\
\hline
\end{tabular}

\begin{tabular}{|l|l|l|}
\hline & Pelaksanaan = \\
& adanya \\
pemahaman \\
tidak \\
melakukan \\
& peminjaman \\
& dengan \\
& sembarangan \\
& melalui aplikasi \\
& FinTech \\
\hline
\end{tabular}

\section{Kesimpulan}

Perubahan cara penjualan dari sistem tradisional ke sistem online tidak semudah membalikkan tangan. Hal ini tergantung dari faktor usia pemilik warung jamu tradisional Bu Hadi. Oleh karena itu disarankan kepada mitra untuk merekrut tenaga atau asisten generasi muda yang melek teknologi untuk membantu sistem pemasaran secara online dan melakukan promosi-promosi yang menarik sehingga bisa menjangkau pemasaran yang lebih luas yaitu generasi muda. Dari sistem pengemasan disajikan dalam botol-botol minuman dengan desain yang lebih menarik.

Pada umumnya saat pandemi COVID-19 terjadi di Indonesia seluruh kegiatan UMKM mengalami penurunan. Perubahan perilaku konsumen yang melakukan pencarian informasi dan pembelian barang atau jasa semakin meningkat maka mau tidak mau banyak UMKM yang harus memperbaiki cara penjualan dan memberi aplikasi kemudahan bagi konsumen untuk melakukan pembayaran secara digital. Perubahan yang 
secara tiba-tiba dan harus diantisipasi dengan cepat untuk mengatasi tutupnya kegiatan usaha ini, antara lain dengan menempatkan pegawai-pegawai yang masih muda dengan literasi media sosial dan memahami e-commerce. Pemerintah dalam hal ini perlu menambah pelatihan-pelatihan digital marketing untuk memajukan usaha yang digeluti UMKM.

\section{DAFTAR PUSTAKA}

Anggraini, Oktiva, Supriyanto, (2019), Literasi Digital: Suatu Kemewahan Bagi UMKM Perikanan di Era Industri 4.0? Prociding Seminar dan Lokakarya Kualitatif Indonesia: Pengembangan Budaya Penelitian Menuju Indonesia 4.0, Jakarta: Universitas Matana, ARA Center, Matana University Tower, 19-20 Maret 2019.

Mangeswuri, D. R., Wuryandani, D., Purwanto, N. P., Hendra, S. P., Meilani, H., Sayekti, N. W., \& Rivani, E. (2018). Industri Kreatif, Fintech dan UMKM dalam Era Digital. In Jurnal Teknologi Informasi.

Media, P., Bagi, S., Kecil, U., Menengah, D. A. N., Di, U. K. M., Raya, M., Di, U. K. M., \& Raya, M. (2018). POTENSI MEDIA SOSIAL BAGI USAHA KECIL DAN MENENGAH. January.

Ningsih, D. R. (2020). Peran Financial Technology (Fintech) Dalam Membantu Perkembangan Wirausaha UMKM. Prosiding Seminar Nasional
Pendidikan Program Pascasarjana Universitas Pgri Palembang, 270277.

Suliyanthini, D., Fashion, V., Education, D., Jakarta, U. N., Fashion, V., Education, D., \& Jakarta, U. N. (2021). Sosiologi. IX(April 2020), $18-24$.

Suwana, F., \& Lily (2017). Empowering Indonesian women through building digital media literasi. Kasetsart Journal of Social Sciences, 38(3), 212-217.

DOI:10.1016/j.kjss.2016.10.004.

Widyartati, P., \& Umkm, P. L. (2017). Pengaruh strategi pemasaran online terhadap peningkatan laba umkm. 20, 343-347.

\section{Laporan:}

APJII, A.P.PJ.I.I. (2016). Penetrasi dan Perilaku Pengguna Internet Indonesia 2016) (apjii.or.id) 